\title{
Higher education and economic development: the importance of building technological capabilities ${ }^{1}$
}

\author{
Glenda Kruss ${ }^{\text {a }}$; Simon McGrath ${ }^{\text {b }}$ Il-Haam Petersen ${ }^{\text {a }}$; Michael Gastrow ${ }^{\text {a }}$ \\ ${ }^{a}$ Human Sciences Research Council of South Africa; ${ }^{b}$ University of Nottingham
}

\section{Introduction}

Higher education slipped down the international development agenda in the past 25 years as first the education for all goals and then the millennium development goals focused on primary education, at the same time as the overall global development discourse put little emphasis on issues of industry-led growth, technological progress and innovation. Yet, since the millennium, governments and populations in the South have largely accepted the discourse of the global knowledge economy, and higher education enrolment growth has been phenomenal, with some national systems in Africa expanding more than ten-fold since 2000 .

Nonetheless, the absence of external support to higher education had a major negative effect on research capacity on education for development in Africa, whilst Northern scholars also largely evacuated the field due to parallel declines in funding. Slowly, research activity on higher education and development is beginning to rebuild internationally. However, there is a paucity of work theorising the relationship between higher education and development, as Oketch, McCowan and Schendel (2014) show in their systematic review of the literature.

What robust evidence there is, shows consistently high rates of return to higher education and points to non-market as well as market benefits (e.g., McMahon 1999). However, the human capital claim that this must reflect productivity gains appears problematic in the face of the highly imperfect labour markets that exist in Southern countries, affected as they are by large public and informal sectors and high levels of patronage (McCowan and Schendel 2015). Whilst there are studies that point to correlations between higher education and innovation (e.g., Pillay 2011), there are counter arguments that point to limited interactions between the key variables of higher education expansion, growth, productivity and technological change (e.g., Ca 2006).

In this paper we want to offer an alternative account of how higher education contributes to economic development. Whilst we acknowledge that there is more to higher education's developmental impact than economic development alone (see Walker 2015, for instance), we will restrict our argument to the economic sphere. This alternative account can be developed by drawing on the evolutionary economics tradition (Nelson and Winter 1982; Freeman 2002; Lundvall 2011), which is being revisited by a number of development economists (e.g., Chang 2014; Salazar-Xirinachs, Nübler and Kozul-Wright 2014). We suggest that evolutionary economics, and, specifically, the national innovation systems approach strongly associated with it, offers distinct benefits in conceptualising higher education's developmental role, due to its stress on the importance of education, skills, work, innovation and production for economic development. Moreover, the focus on the level of the organisation (typically the firm, but the university by analogy) and network offers a new

\footnotetext{
${ }^{1}$ The research was conducted under the Labour Market Intelligence Partnership, a research consortium led by the Human Sciences Research Council, South Africa, and funded by the Department of Higher Education and Training. We acknowledge a large team of researchers who participated in the data-gathering and analysis process, as well as all of those who participated in the case studies.
} 
scalar level and methodological purchase on the higher education - economic development relationship. Together, these theoretical and methodological lenses offer very different policy implications and possibilities when compared to more conventional neoclassical approaches. Such alternatives may be of value for consideration alongside or in competition with orthodox policy options.

In this paper, we locate our research in this broad approach, but our focus is on the explanatory potential of mid-level theories of technological capabilities (Lall 1992 and 2001), sectoral systems of innovation (Malerba 1999, 2002 and 2005) and interactive capabilities (von Tunzelmann and Wang 2007; Von Tunzelmann 2010). Using these concepts, we examine the complex ways in which South African higher education is positioned to contribute to economic development. We do so through a consideration of two case studies: the high skills case of the astronomy sector - particularly the Square Kilometre Array (SKA project) - and the automotive sector - specifically the "tier 1" component supplier sub-sector in the Eastern Cape.

Given that much of this literature may be unfamiliar to education audiences, we will proceed to a relatively lengthy discussion of key concepts and approaches before reporting on the methodological approach taken. We will then examine two sectoral case studies separately through the lenses of our conceptual framework before drawing them together in a conclusion that considers the theoretical, practical and policy significance of such an approach to thinking about higher education and economic development.

\section{Literature review: Evolutionary economics and innovation systems}

Following the perceived failure of efforts to understand variations in country development and growth patterns through conventional neoclassical approaches, a series of alternative approaches emerged emphasising the role of innovation in economic development, underpinned by evolutionary economics (Lundvall 1992; Nelson 1993; Freeman 1995). Nelson and Winter (1982) pioneered the argument that productive transformation is central to economic development. Contrary to linear models of technological development that privilege the knowledge frontier as the locus of economic growth, these scholars argued that innovation is a non-linear and non-sequential process. Moreover, drawing on the institutional tradition, they stressed that technical change and growth depends as much on social as on technical innovations. That is to say, it requires multiple processes occurring simultaneously in production, which in turn requires not just research and development capacity but a variety of skills at all levels of the firm, and processes and systems for harnessing these in order to ensure effective diffusion and adoption of technology (Freeman 1995; Dosi 1998; Lundvall et al. 2002).

\section{Technological capabilities}

Within development economics, this approach was taken up most prominently by Lall (1992 and 2001). He stressed that technology cannot simply be imported without investing in the technological effort to master, acquire, adapt and improve upon existing technologies (Lall and Kraemer-Mbula 2005). This is crucial, for it goes against core assumptions of the neoclassical theory of trade by highlighting the difficulties that developing countries actually face in making technological and industrial progress. Lall's work stresses that it is through building capabilities to learn that a country grow its ability to catch up. Capability building involves effort at all levels of a firm, as well as new skills and knowledge that are required to master tacit elements of new technology. Lall's "capabilities" approach not only proposes 
that learning requires organisational capabilities, but also highlights the national level, stressing that countries also need to learn to be technologically capable, an important contribution to the notion of the developmental state.

This implies an important role for networks as the means of bridging between the firm and national economy levels. Thus, the approach focuses on linkage capabilities between actors in the national system. Science and technology links and knowledge exchange with universities, research organisations and other organisations are critical for technological capability building, but equally so are linkages to those organisations or actors that build the skills required at all occupational levels of the firm.

More recently, Salazar-Xirinachs, Nübler and Kozul-Wright (2014: 2) argue in this tradition that productive capabilities determine the realistic options for economic diversification and the competences to take advantage of potential opportunities: "Learning builds up dynamic capabilities which are key drivers of catching up and economic development". Thus, according to this account, a core role of an aspirant developmental state is to support learning processes to develop dynamic technological capabilities at all levels (Salazar-Xirinachs, Nübler and Kozul-Wright 2014).

\section{Sectoral systems of innovation}

Arising from an earlier focus on national systems of innovation (e.g. Lundvall 1992; Nelson 1993), a literature emerged that focused on sectoral systems of innovation (SSIs), which places the emphasis on economic sectors as potential key agents of economic development. Malerba (1999: 4) defined an SSI as:

A set of heterogenous agents carrying out market and non-market interactions for the generation, adoption and use of new or established technologies for the creation, production and use of productions that pertain to a sector.

SSIs are dynamic systems shaped by the coevolution of their components. It is assumed that firms in a sector search around similar knowledge bases to inform their productive activities, face similar technologies (and challenges related to national and global technological development), undertake similar productive activities and are influenced by the same institutional environments (Malerba 2005). However, firms will also be influenced by their previous learning experiences, competences, organisational routines and culture, and opportunity conditions. Thus, the knowledge base of the firm and accessibility of appropriate technologies may act as both the foundation for and a constraint to innovation and learning. Equally, the nature of sectoral networks may also serve to limit or facilitate the acquisition of knowledge and technologies.

Innovation is a networked activity shaped by the agents with which a firm interacts and by the institutions within which they and other actors are embedded. The networks of actors include interaction between firm and non-firm organisations, and individuals (e.g., scientists, entrepreneurs) connected through market and non-market relations. Rather than placing the actors at the centre of the analysis, the approach "places dynamics, process and transformation at the centre" (Malerba 2005: 64).

\section{Interactive capabilities}

The work of Von Tunzelmann (2010; von Tunzelmann and Wang 2007) provides the third component of our conceptual toolkit. Building on the insights of the previous accounts, von 
Tunzelmann highlights the centrality of interaction between the key actors in the innovation system. His model is three-fold, stressing the importance of, and the important distinctions between competences, interactive capabilities and dynamic interactive capabilities.

Von Tunzelmann's work builds on the older technological capability literature in a way that highlights the importance of specific sets of capabilities required for effective strategic interaction, and provides concepts to differentiate and distinguish between these.

"Competencies" stem from inputs to produce goods and services, that is, the pre-set attributes of individuals and firms, typically produced through education and training (von Tunzelmann and Wang 2003). They take two key forms:

- tacit knowledge embodied in the human resources of the organisation and organisational routines; and

- codified knowledge present in organisational structures, technologies, formal policies or other physical resources.

Thus, the recruitment of university graduates or artisans may be a necessary internal competence for firms that want to adopt new technologies. However, merely employing those graduates or qualified artisans does not guarantee learning or the successful adoption of new technologies.

This requires "interactive capabilities" - defined as the capacity for learning and accumulation of new knowledge on the part of the organisation, and the integration of behavioural, social and economic factors into a specific set of outcomes (von Tunzelmann and Wang 2003 and 2007).

In the context of dynamic change - in terms of dynamic competition and institutional change - actors require an additional set of capabilities, which allow them to effectively and efficiently respond to non-routine changes in circumstance. Changes in circumstance and the environment also often result in changes in the organisations' capabilities. Von Tunzelmann and Wang (2007) refer to such capabilities as "dynamic interactive capabilities" in order to distinguish the interactive capabilities necessary for routine activities and those interactive capabilities supporting greater flexibility in responding to dynamic changes in circumstance. Pavlou and El Sawy (2011) identify four dynamic capabilities: sensing, learning, integrating and coordinating.

Figure 1 below provides a generic conceptualisation of the actors and potential flows and interactive learning in a sectoral system of innovation (SSI) in the South African context. It provides a framework for mapping the SSI, as a basis for studying networks and interactions, and the interactive capabilities of the main actor. 
SKILLS DEVELOPMENT

SMME

Large

MNCs

Other
MECHANISMS/STRATEGIES

SKILLS SUPPLY

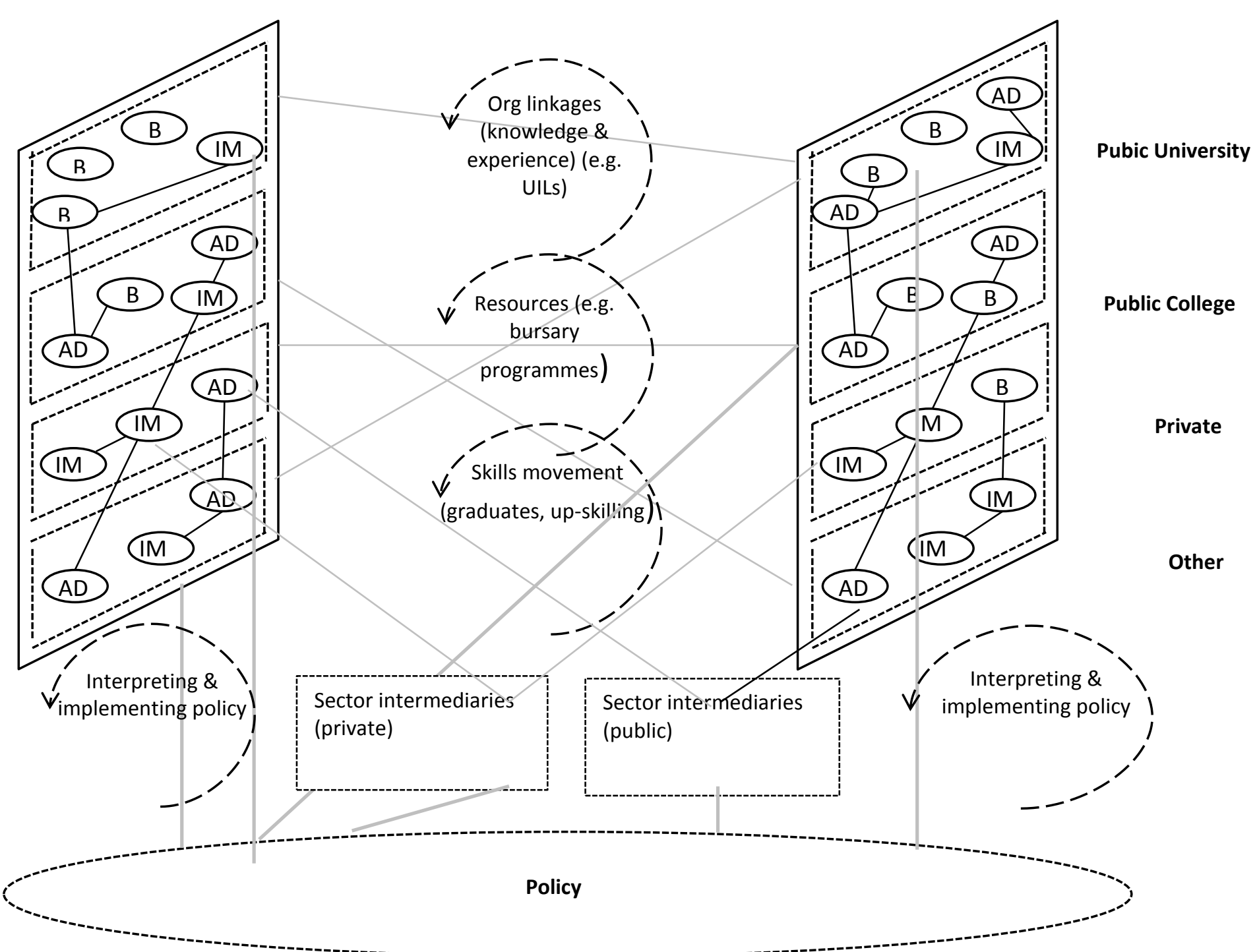


The ability of an organisation to effectively and efficiently respond to changes in business and institutional environments depends on the appropriate use of its competencies through its organisational processes and/or routines. Management thus needs to identify (or sense) changes in the environment that present opportunities, threats or constraints to the organisation, and identify the organisation's competencies and capabilities to respond, through its organisational routines. An appropriate response requires the exploitation of the organisation's competencies and capabilities, and often involves the acquisition of new knowledge and competencies which transform and are transformed by the organisation through learning. The new knowledge and competencies then need to be integrated into existing organisational structures and processes. It is important to note that units within organisations can differ in terms of their interactive capabilities. Most importantly, the success of this process hinges on the effective coordination capability of management and leadership.

Knowledge and information flows between actors in interaction, and the co-evolution between actors and the wider institutional contexts in which they are embedded, are also important. Hence, the role of alignment in capabilities and goals between networks of actors in the sub-systems that make up an innovation system is critical.

\section{Bringing an education perspective to bear}

The evolutionary economics and innovation systems literature has almost entirely been applied to firms and, whilst stressing the centrality of learning, has had minimal engagement with literatures on education and skills development. While higher education is a focus, it is primarily researched in relation to its value as a source for firm learning. Thus, part of the contribution of our research is to build a bridge between these accounts, and aspects of educational theory. We take the innovation systems literature into the educational space by looking at how interactive capabilities are developed and nurtured within the higher education sector at organisational level; the role that sectoral skills development intermediaries play in this process; and how this engages with the higher education policy arena. While the key concepts have to date been applied to firms, it is evident that they are highly transferable to analyse the capabilities of other, non-market actors such as higher education organisations, in relation to their capacity for learning to attain strategic national or organisational goals.

Figure 2 provides a schematic view of how capability building in a higher education institution might be conceptualised. 


\section{CAPABIITY BUILDING PROCESSES: EDUCATION \& TRAINING ORGANISATIONS}

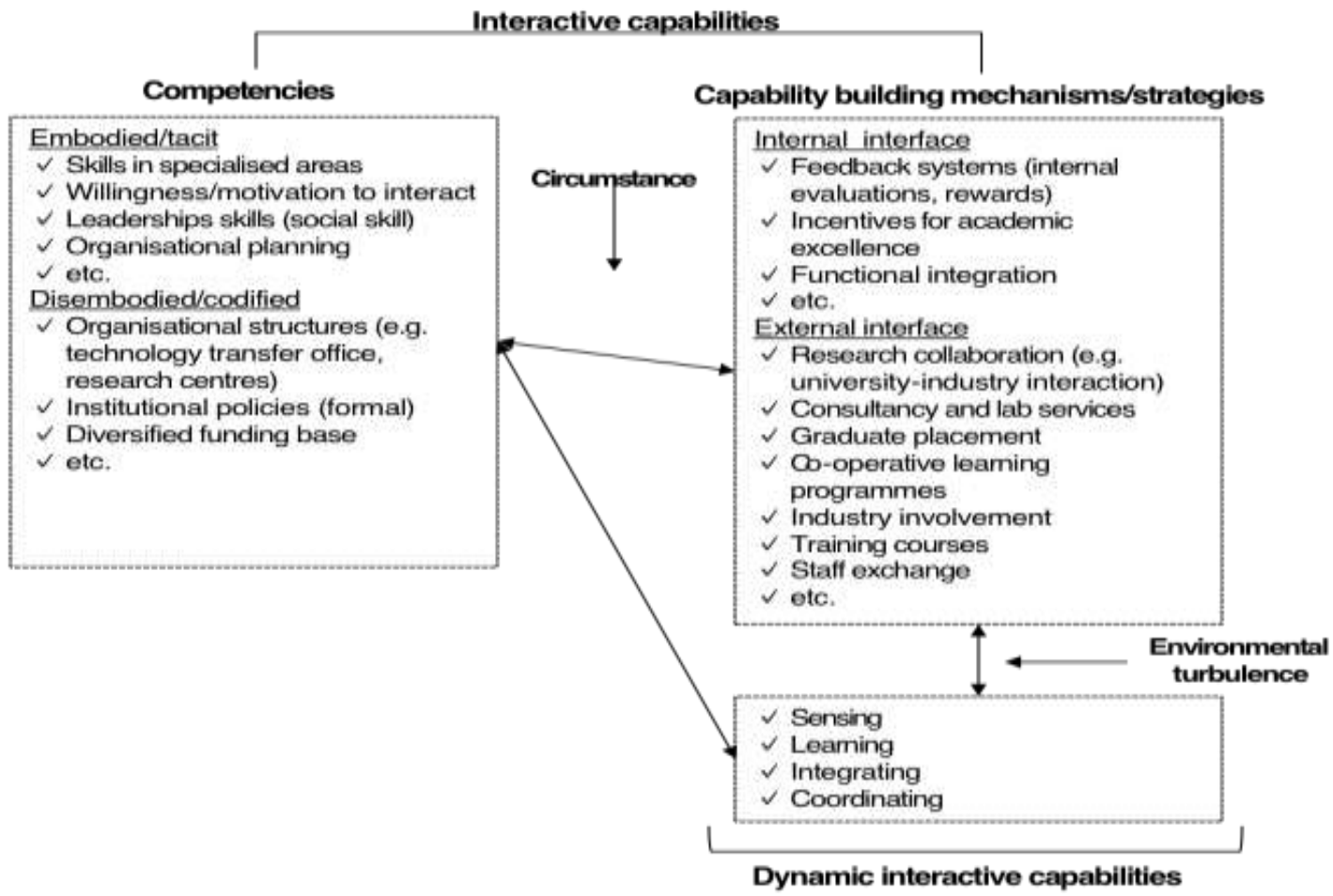

In bringing these concepts from innovation studies into an educational study, the resonance of the approach with new political economy of skills accounts (Crouch, Finegold and Sako 1999; Brown, Green and Lauder 2001; McGrath et al. 2004) becomes obvious. Like the innovation literature, the new political economy of skills stresses complex social, cultural, political and economic interactions, and sees these as evolving over time. The precise synergies and dissonances of the two approaches, however, must be the subject of another paper.

\section{Research design}

We designed a methodology to investigate the structure, agents, strategies and mechanisms that organisations use to build dynamic interactive capabilities and skills in diverse economic sectors with specific technological challenges. The unit of analysis was the interaction between the main actors in the education and training organisations, firms and sectoral intermediaries within an SSI, from which challenges and bottlenecks to inform policy interventions can be identified. The approach requires data describing the key actors (firms, universities, colleges, government agencies) and the relationships between these actors, with a focus on the generation and movement of skills (Lorentzen et al. 2011).

The design centred on a large scale, multi-level case study methodology. Three broad sub-sectors were selected, one each in the primary, secondary and tertiary sectors ${ }^{2}$. The first task was to define the bounds of a SSI as unit of analysis, so that it could be empirically researched. This was achieved through background studies of each sector that mapped key value chains, technological change and employment patterns, in terms of regional concentrations of productive activity. A study of the policy frameworks and mechanisms that shape national economic growth and in each sector was included in this process.

The next step was to map all the actors involved in the sectoral system in the region, and to focus in on key locations of intense economic activity. Interviews were conducted with all the actors in the SSI. Interviews

\footnotetext{
${ }^{2}$ In this paper, we do not include analysis of the sugar growing and milling sector, the primary sector case study, as it is less concerned with higher education.
} 
were conducted with a purposive selection of firms representing national and multi-national firms of different sizes, to determine their skills needs and strategies used to address these. All sectoral intermediaries were interviewed, to understand their roles and linkage mechanisms.

For universities, we interviewed all those located in the region, plus significant universities outside the region, to understand how they are organised to respond to the sector's skills needs, in general such as curriculum structures or career placement services, and in terms of mechanisms specific to that sector (such as a technology hub or training programme). Interviews were conducted with senior organisational managers and with deans or heads of key faculties and departments. A similar process was conducted for the other post-school education and training (PSET) organisations, such as technical and vocational colleges, private providers, agricultural colleges or apprenticeship programmes. ${ }^{3}$ A set of templates was developed for use in the interviews and a team of interviewers with experience in each economic sector or PSET subsystem was trained to work with a lead synthesis author for each case study. All respondents also took part in a social network analysis that provided an assessment of the reach and strength of interaction between actors (who was working with whom, how intensely and in what ways). In total, 153 interviews took place across the two cases reported in this paper: 72 for the SKA and 81 for the automotives case study. The fieldwork evidence base was supported by additional desktop research, including materials provided by universities and other actors.

\section{Evidence from two case studies: higher education in the SKA and automotive sectoral systems of innovation}

South Africa is an upper middle income country grappling to escape the well-documented structural constraints inherited from the colonial and Apartheid past. In recent decades there has been major growth in tertiary economic sectors and in high skills occupations, accompanied by growing unemployment, poverty and inequality (Bhorat, Goga and Stanwyx 2013). The response has been to propose a developmental state model that is driven by stronger planning and monitoring of government outcomes. Since 1994, a deliberate set of science and technology policy instruments has promoted the development of a national system of innovation, prioritising big science, technology transfer and the growth of niche competences and capabilities. The Department of Higher Education and Training, formed in 2009, has promoted the creation of a single post-school education and training sector, with a stronger message about employability and responsiveness than in the past.

Higher education interaction with industry in the forms of collaborative R\&D and innovation has been incentivised by the Department of Science and Technology. The national system of innovation remains characterised by 'islands of innovation', of cutting edge activity at the technology frontier in selected niche areas, while firms in most sectors struggle to raise their levels of productivity and technological capabilities to compete more effectively in regional and global markets (OECD 2007; DST 2012).

Our two cases in some ways reflect this tension, and highlight the uneven role of the higher education system in distinct sectoral systems of innovation, in an increasingly globalised economy. Thus, the South African automotive sector is at a disadvantage globally, as it does not have access to large domestic markets as in China or India, or even Brazil where there is access to large regional markets in Latin America (Gastrow and Kruss 2013). Moreover, our case study of tier 1 suppliers is located in a province that is one of the poorest in South Africa, the Eastern Cape, with high levels of unemployment, poor infrastructure and low levels of educational achievement. The SKA case in contrast, is premised on South Africa's geographic advantage to host radio astronomy telescopes, and is strongly inserted into global innovation networks.

\section{Meeting routine skills needs in the Tier 1 automotive component sector in the Eastern Cape}

In countries like China and India, the automotive sector has succeeded in technological capability building to the extent that local firms have become part of global innovation networks, and in turn, have created national industries that are globally competitive (Gastrow and Lorentzen 2013). The automotive sector in

\footnotetext{
${ }^{3}$ This will be the subject of a subsequent paper.
} 
South Africa however, remains strongly disciplined by global production chains, and research and innovation is conducted primarily at multi-national headquarters. All the large original equipment manufacturers (OEMs), and many of the Tier 1 component firms in the study, are multinational corporations, and the decision to stay and invest in their South African operations is subject to frequent reappraisal.

Government has prioritised the sector in its industrial policy strategies, and the sector is well organised into industry associations, with strong trade union presence. In the Eastern Cape, the sector is high in provincial and metropolitan economic development priorities and structures, and there is proactive interaction from two large industrial development zone initiatives. This has resulted in a rich set of public and private intermediaries that reflect both the sector's own internal organisation and the priority placed on it by national and provincial governments, resulting in a complex network of relationships and activities, with significant additional resourcing for skills development. Through and beyond these, actors from industry, government and skills providers meet regularly and have some sense of a shared understanding of and commitment to the automotive sectoral system. There is some evidence of capabilities regarding strengthening innovation, quality systems and human resources management in a range of firms, but including only a few components manufacturers.

Nationally, a sectoral prioritisation and development programme initiated by the Department of Trade and Industry has been successful in that its incentives have kept the South African sector alive - but it does not provide a model for productive transformation. The programme did not include specific mechanisms to promote skills development, and its benefits have been dominated by the small group of OEMs. The main component firm actors and sectoral intermediaries do not have coordinated strategies to promote research excellence or sector-specific skills. Industrial policy has recently prioritised technological capability building in the national components sector, and this is stimulating new initiatives around supporting sector specific-skills.

Equally, the capabilities of the provincial post-school education and training system to interact within the sector are directed primarily at OEMs such as Mercedes-Benz, Volkswagen and General Motors. Firms interviewed did not identify skills shortages as a constraint on their operations, but there is strong concern for process-level efficiency to reduce costs. This leads to a drive towards higher levels of skills but fewer staff. As much as $70 \%$ of employment is at basic operative levels, with relatively little current demand for intermediate skilled workers or high level engineers. Firms have developed effective strategies to address their routine skills needs, and many do have the capacity to deliver in-house training or source courses from private training providers. The sourcing and upgrading of engineers is typically managed through interaction with universities, through bursary programmes, student placements and internships or leadership training.

In short, firms have the capacity to meet their routine skills needs, and interact with universities in traditional ways, to meet their high-level skills needs. The majority of HR managers interviewed acknowledge the existence of valuable relationships with public providers. However, our analysis suggests that the component sector is constrained by weak dynamic interactive capabilities. It has not concentrated sufficiently on sectoral coordination and networking directly aimed at building capabilities for technological upgrading, so that it can be inserted more favourably into global production chains and innovation networks. As a result, interactions with higher education appear fragmented and limited.

Figure 3 draws on the social network analysis and reflects the thin networks of Tier 1 firms, and in particular, the limited scale and intensity of interaction with the four universities in the province, as reported by the 21 firms interviewed. Firms were most likely to interact with intermediary industry organisations, other suppliers and OEMs. 


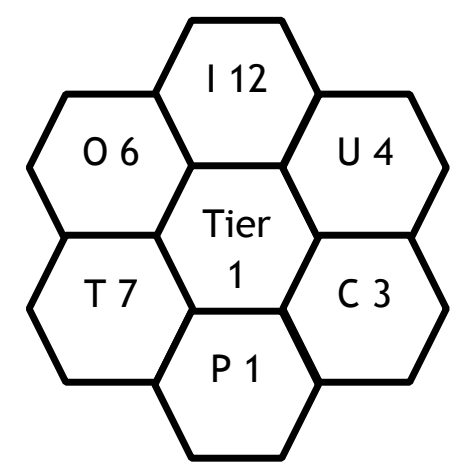

Note: I=intermediaries; $U=$ public universities; $C=$ public colleges; $P=$ private providers; $T=$ tier 1 firms; $O=O E M s$. The numbers represent the mean weight for that category of network actor of relationships calculated as the product of the number of partnerships and their relative strengths, as reported in the network survey.

Further inspection revealed that on average, each tier 1 firm had one interaction with a PSET organisation. Approximately half of these were with public universities. Only a quarter could be described as relatively intense and wide-ranging. In the higher education sector, almost all of these thick relationships were concentrated in only one of the four public universities in the province. Such interactions included participation in an innovative Formula Student project which produces a racing car to compete internationally; collaboration on course design; and the payment of generous stipends and bursaries to learners. The capacity to work with the automotive sector has been built through interaction in the form of international partnerships; income generation from short courses and training contracts; and infrastructural, materials and staff development, much of this supported financially and brokered by intermediary organisations. However, it was evident that firms treated such relationships largely in an ad hoc way, and to address specific short term problems.

The question is the extent to which this network misalignment may be attributed to the interactive capabilities of the four universities. Our analysis suggests that whilst all of the universities do have some interactive capabilities, as reflected above, one university has the strongest concentration, reflecting in part its location near main OEMs and its long history of producing engineering graduates. A key issue in relation to the competences of the universities is that three are still in the process of building new institutional identities following the national process of higher education merger around 2004, with very uneven progress to date. One university has been under administration, and clearly has weak tacit and codified competences and interactive capabilities in relation to interacting with the automotive sector. Two universities are located in small towns away from the core of the industry and predominantly offer Humanities programmes, with less than a quarter of their students registered in science, engineering and technology (SET) fields. These three universities provide graduates who may work in management or on the business side of component firms located in their region. There are a few linkages around management training programmes in these universities, but there are no structured SET-oriented programmes.

The comprehensive university in which most of the interaction is concentrated is the result of a merger between a former technikon (polytechnic) and a former university. The former technikon had a strong practice of industry interaction, which provides strong institutional culture, leadership and disciplinary competences with which to interact. The merged university has a clear employability-driven view of graduate attributes and a legacy of work integrated learning linking students and academics to industry. The university's interactive capabilities are reflected in external interface structures such as sectorally-funded research chairs (Volkswagen, General Motors, merSETA- the statutory sectoral training authority) and research units, and a technology station funded by a national innovation agency that focuses on technology transfer to small enterprises in the automotive component industry, by supplying design and prototyping services. Another critical external interface structure is the programme advisory boards inherited from the technikon tradition. In terms of dynamic interactive capabilities, the university has a strong institutional 
planning structure that informs strategic planning, quality enhancement and monitoring and evaluation of progress, which reflects its sensing and integrating capabilities.

We have described these examples in some detail here, to illustrate how the framework can be used to differentiate between the universities within a sectoral system of innovation, in terms of their interactive capabilities. This helps us make the larger point that this methodology offers important new insights for those thinking about higher educational planning at institutional and national levels, and about science, technology and industry policies. In this sectoral system, clearly there are gaps in the interactive capabilities of some universities, but the capabilities of the comprehensive university are sufficient to meet the routine skills needs of firms in the sector.

However, if South African tier 1 firms are to be more competitive locally and internationally, then there is clearly a role for skills development. More universities in the region need to develop the dynamic interactive capabilities to network with component firms, to be able to address changing skills needs. In terms of technological capability building for economic development, the universities in the region could support local firms in tiers 1 and 2 more effectively, whether through their graduates, research, technology transfer or training. As the main knowledge producers in the network, universities can contribute to enhance firm learning, if firms are to become more proactively inserted in global production networks. There are no guarantees that a more innovative automotive components cluster can be achieved, given the global constraints and disciplines under which it operates. Nonetheless, there is a pressing need to support the sector to continue as an important contributor of employment, exports and skills; and the potential to support it further through enhanced national policies and improved local higher education organisations.

In contrast, in many senses, the SKA is a success story of skills and technological capability-building. Its success depends on the ability to connect skills, knowledge, technologies, networks, intermediaries and funding, in order to deliver the world's largest science project in a developing country. Astronomy has emerged as a growing niche within South Africa's national innovation system, evident in the rapid growth of radio astronomy. Geographic advantage has been successfully leveraged by long-term public sector support, including policy measures to protect geographical areas suitable for astronomy, and sufficient funding to establish competitive world-class astronomy facilities. From the early stages of the SKA bid, it became clear to strategic movers that geographic advantage would have to be complemented by hugely increased capabilities in terms of astronomy and engineering, in order to tilt the odds of success sufficiently in South Africa's favour, and to justify the large investments that would have to be made.

The mapping and social network analysis revealed a complex and densely connected network with a number of large nodes and strong degrees of interaction, that included universities, science facilities (such as large national telescopes), research institutes, firms (largely engineering firms), local and international intermediaries (both public and private), and government agencies at the national level. Rapid technological changes in the sector and uncertainty as to future technological pathways meant that the dynamic interactive capabilities of all actors are critical. 


\section{Figure 4: Network map illustrating the skills development networks in the astronomy sector for the SKA}

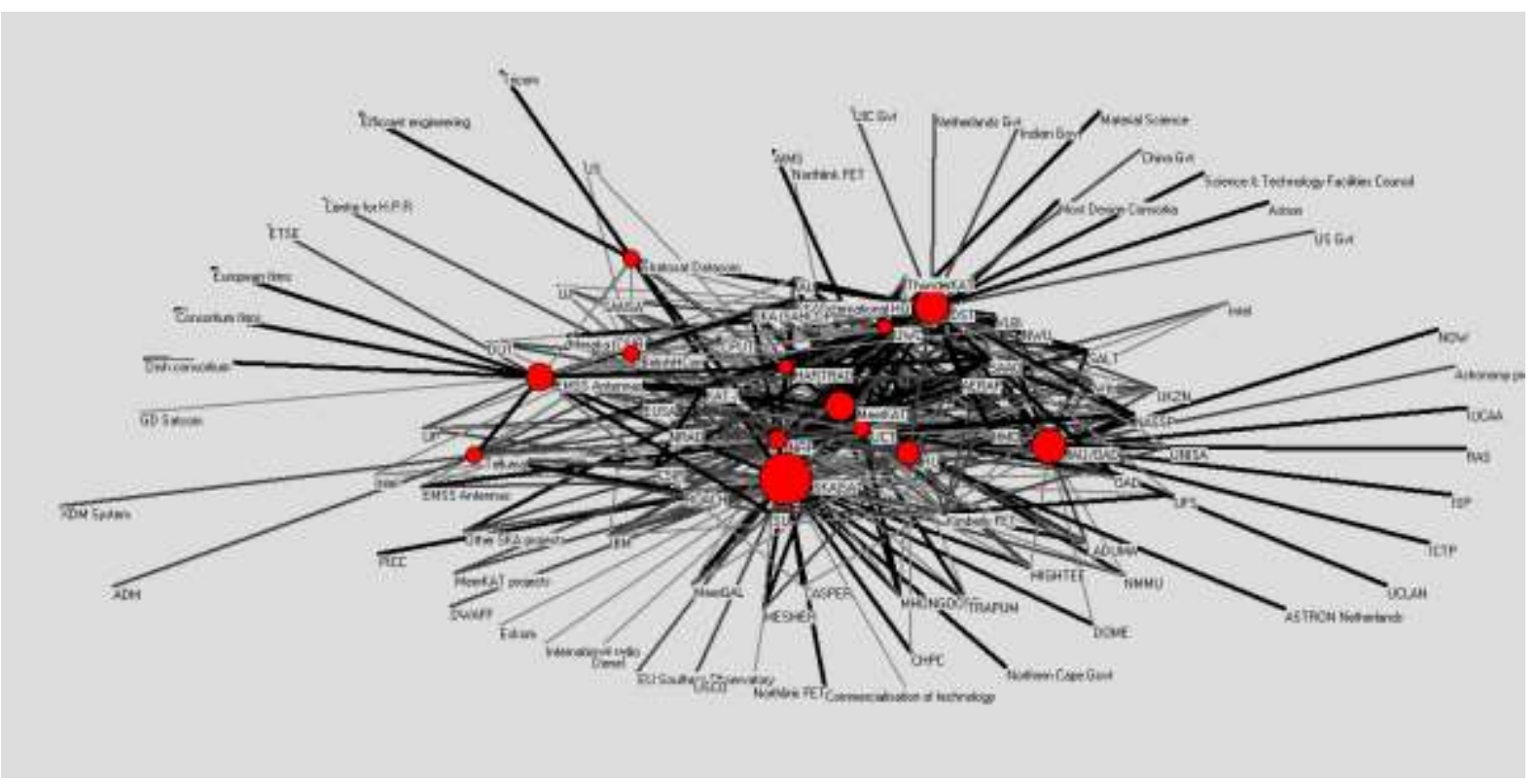

The SKA network in fact can be interpreted as a set of inter-connecting global innovation networks, each centred on specific scientific or engineering projects. A strong degree of network alignment is evident in the explicit shared emphasis on the goal of increased technological capabilities, in terms of the high demand for astronomy and engineering skills. Highly coordinated skills development efforts were rolled out from an early stage of the SKA bid process, which required intensive interaction between actors on the skills demand and skills supply sides of the sectoral innovation system. Among public sector intermediaries, government departments of Science and Technology and of Higher Education and Training, and the National Research Foundation each deployed interactive capabilities to develop strategic approaches to the planning and funding of sector-specific skills development. This has included dedicated funding for research chairs and for a student development programme. A high level of funding from government actors has been channelled into the public higher education system, together with focused mentoring and support for individual students. These new programmes have rapidly grown the competences available to employers, and greatly increased South Africa's capabilities and competitiveness in the international arena over the last decade.

Several forums, both formal and informal, have been established through which the main employers in the sector engage with the main PSET organisations in order to align curricula, research and funding. These include forums based within universities, such as a national Astrophysics and Space Sciences programme, as well as those based within science facilities, such as the SKA's Human Capital Development Programme. More importantly, perhaps, strong informal linkages exist between individuals and organisations, generating widespread awareness of skills demand and skills supply issues among all the major actors.

Six research universities are central actors in the astronomy SSI, producing much of the necessary skills and knowledge. Figure 5 illustrates the strength and density of university networks with the SKA, other universities, firms and intermediaries. Firms interact most strongly with the SKA (mean weight of 59, calculated as the product of the number of linkages and their relative frequency, as reported in the network survey); then, with universities (a mean weight of 29), followed by other firms and science facilities. Notably, firms interact with 11 universities, going beyond the six core university actors. The network thus has both greater depth and breadth than the network at the heart of the automotive SSI. 


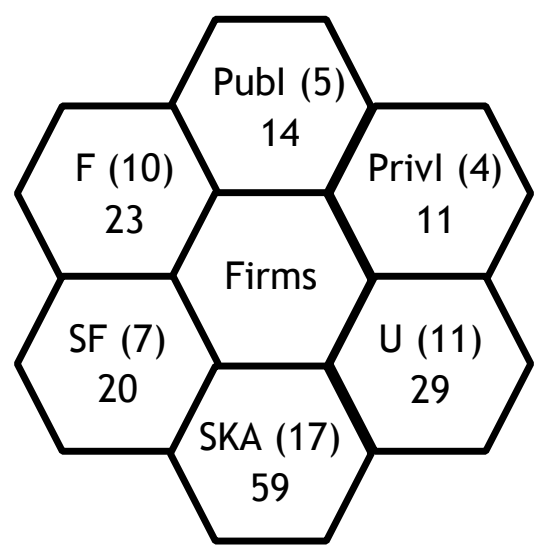

Note: F=Firms; PubI=Public intermediaries; PrivI=Private intermediaries; $U=$ Public universities; SKA=the SKA project office in South Africa; SF=Science facilities. The numbers represent the mean weight for that category of network actor of relationships calculated as the product of the number of partnerships and their relative strengths, as reported in the network survey. The number of organisations included in each sub-group is indicated in brackets.

Within research universities, department of physics, mathematics, computer science and engineering are the most relevant to the skills needs of the sector. Only one university hosts a department of astronomy, which has been a key actor. The availability of high-level niche competences in the fields of astronomy, engineering, mathematics and ICTs are a necessary condition that explains why some universities are more central to the network than others. The "big science" model of collaboration is familiar to many of the actors, even if the specifics of the SKA are novel.

Interactive capabilities at the organisational level play an indirect role in driving the interaction, but a direct role in enabling it. The overall efficacy of functions such as institutional planning, teaching and learning, internal capability-building and student support all impact on the overall quality and quantity of graduates emerging from a university, and on the university's research capabilities and reputation. Research offices, contract offices, technology transfer units and departmental level structures are strong internal and external interface mechanisms that support the network directly.

Coordination of the formal, codified engagement with universities takes places through an external interface mechanism of the SKA, a Universities Working Group. The group meets on a regular basis to discuss the progress of the project, the scope of research projects, and any other items of relevance to the interaction between universities and the SKA. This forms one of the most important interactive mechanisms in the SKA's innovation network, providing a unique and critical point of engagement between the skills supply and skills demand actors. The group is informally arranged, and has no formal mandate. Again, this highlights the key role that informal relationships and informal networks play in the network.

The specific mechanisms that facilitate interaction within the universities are largely based within faculty or department structures. At this level, interactive capabilities in the domains of teaching and learning, and research and innovation, emerge as the primary points of articulation with the astronomy sector. In both of these areas universities have adapted the scale and scope of their teaching and learning, and research activities to align better to the changing needs of the astronomy sector in general and the SKA in particular.

However, there is a clear distinction between the profile of interactive capabilities for science and for engineering. Interaction in engineering occurs through a more formalised, complex and structured set of mechanisms, including advisory boards, a five-year review process, academic time allocations for working with industry, contract R\&D for industry, funding for equipment, close engagement with the engineering professional body, invited speakers from firms and strategic interaction with government. 
In science, informal mechanisms for interaction play a greater role. The main capabilities that have had a tangible effect on interaction are the existence of personal and professional relationships between SKA management and scientists and university-based scientists, and the role of research chairs in establishing critical mass in knowledge and technology domains required by the SKA. These relationships evolve over time - thus historical trajectories have a tangible effect on the structure of interaction. Relationships built on the basis of previous collaborations endure, and continue to structure new projects and partnerships. Therefore, the interactive capabilities vested in individual academics, particularly premised on tacit competences for interaction that facilitate the maintenance of informal networks, have played a central and catalytic role. The rewards and benefits for academics and their universities are considerable, creating an impetus for further collaboration.

The SKA case thus illustrates that within South Africa's unequal higher education system, pockets of excellence exist where resources and networks are concentrated. These can be strategically leveraged to attain global competitiveness in niche areas, but this requires risk-taking, funding, coordination, strong dynamic interactive capabilities and strategic skills planning.

\section{In conclusion: a new approach to thinking about and planning higher education for development?}

Here we will argue that the approach offers an important alternative to the current way of thinking about higher education's contribution to economic development. Of course, this account does have its limitations. From a political economy perspective, we know that higher education supply-side improvements cannot in themselves substitute for adverse demand-side trends. The demand for quality graduates is profoundly shaped by the global workings of capitalism and decisions about production locations and technology mixes. In the South African context, we have pointed to the severe constraints that act to limit the routine demand for graduate skills. Any use of the approach we advocate needs to take such national and global dynamics carefully into consideration. Finally, we need to stress that higher education's purpose is not reducible to the economic domain. Rather, we seek to engage with the debate around one of higher education's multiple purposes - the production of skilled graduates for the economy - in new ways. We argue for a reconsideration at the theoretical, policy and institutional strategy levels, in this final section.

\section{Theoretical significance}

Significantly, our analysis of the two cases stresses the importance of the intersection between the global, national, sectoral and spatial dimensions when thinking about the connection between education and economic development. It shows how these vary considerably and how dynamics at multiple scalar levels work in complex ways to shape possibilities for development. Together, these reinforce the orthodox comparative education argument that "context matters" (e.g., Crossley and Jarvis 2001). It is also reminiscent of the arguments of the early German theorist of the political economy of development, Friedrich List, regarding the place that education, and institutions, play in national development, a concern that has been taken up very clearly in the innovation systems approach (List [1841] 1991 - see Winch 1998 for an account of List's value to educational thinking about development as compared to Adam Smith).

We argue that such an approach offers a way forward for international education and development thinking about the relationship between education, technological innovation, production and development. This is particularly significant as policy and research interest in higher education and development begins to revive. Our approach, we believe, is attractive for an educational audience as it puts learning - in firms, education and training or intermediary organisations - at the heart of analysis. In highlighting the role of actors and their interaction in networks - firms, higher education providers, intermediary organisations - the approach also allows us to move away from the currently dominant neoliberal accounts that focus simply on the responsibility of higher education to become more responsive to firms. Indeed, the approach balances the focus on actors with a stress both on policies and sectoral, and wider, institutional dynamics. The focus on interactive capabilities deepens the analysis of agency, exploring how academics and their organisations have the will, capacity and skills to interact with firms, with the possibility of mutual benefit. The approach also points to important methodological possibilities for researching higher education and development. 


\section{Policy significance}

The technological capability approach offers a radically new way of thinking and acting about the role of post-secondary education and training institutions in supporting national development goals. A focus on technological capabilities emphasises how innovation and improvement come about through learning and communicating. It shifts attention towards economic sectors and how the post-school education and training system supports them. Rather than a focus on central planning mechanisms and structures, it highlights the need to build capabilities within organisations, networks and systems to be able to learn and innovate. This implies a need to have an enhanced understanding of the capabilities of PSET organisations to shape their core education and training activities. The success of the SKA case in growing skills for technological advancement implies that significant gains can be achieved through sectoral science and technology policies focused on interactive capabilities. However, the automotive case serves as a cautionary tale about the need for a view of the realistic possibilities for development. This is in contrast to many national development policies' rather glib statements of intent to become knowledge economies, and the tendency for these policies to prioritise the same few target sectors without any sense of national capacity to make this a reality within the global capitalist system.

We are not making an argument for the state to 'build' sectoral innovation systems. Rather, the creation of a distributed process of capacity development and network enhancement is a task in which the state must work particularly strategically with private and public intermediary organisations, as well as education and training organisations themselves.

The approach emphasises the crucial importance of building domestic firms' capabilities, which suggests the need for more targeted industrial policy than has hitherto been the case. An innovation system is multi-scalar in nature and this requires policy approaches that can ensure that decisions are made at the appropriate scalar level.

A focus on learning, capabilities and interaction enables the identification of weaknesses that may lie within organisations, related to their capabilities, or externally within the system itself, including misalignment between networks, missing organisations and critical blockages of flows of knowledge and resources.

\section{Strategic significance}

Universities need an enhanced understanding of how they can respond to the changing technological capabilities and skills needs of firms, particularly in relation to their professional and occupational programmes. More significant, the emphasis on interactive capabilities assigns greater agency to universities as actors. Universities need to focus more on what their own capabilities are; how they capture their own tacit knowledge more effectively; and how they develop their capabilities more strategically, in relation to priority sectors that match their expertise, whether in their immediate contexts or nationally. This requires a stronger focus on organisational learning - through sensing change, coordinating and integrating new mechanisms and structures within the university. It requires a clearer strategy, structures and mechanism for communicating with firms, sectoral intermediaries, government and other knowledge producers.

Conventional approaches to institutional responsiveness focus solely on what education providers should do better, couched largely in deficit terms. In contrast, this approach focuses more on the positive aspects of learning and on becoming more capable. There are equally strategic implications for firms, which are encouraged to enhance their understanding of dynamic demand, and of the network of PSET organisations with whom they can work, and the ways in which they can align their interests more effectively. 


\section{References}

Bhorat, H., Goga, S., Stanwyx, B., 2013. Occupational shifts and shortages: skills challenges facing the South African economy. LMIP Report 1, Human Sciences Research Council, Pretoria.

Brown, P., Green, A., Lauder, H., 2001. High Skills. Oxford University Press, Oxford.

Ca, T., 2006. Universities as drivers of the urban economies in Asia: The case of Vietnam. World Bank Policy Research Working Paper 3949, Washington.

Chang, H.-J., 2014. Economics: A User's Guide. Pelican, London.

Crossley, M., Jarvis, P., 2001. Context matters. Comparative Education 37, 4, 405-8.

Crouch, C., Finegold, D., Sako, M., 1999. Are Skills the Answer? Oxford University Press, Oxford.

Department of Science and Technology, 2012. Final Report of the Ministerial Review Committee on Science, Technology and Innovation Landscape in South Africa, Gazette No. 35392, Government Printer, Cape Town and Pretoria.

Dosi, G., 1988. The nature of the innovative process. In: Dosi, G., Freeman, C., Nelson, R., Silverberg, G. and Soete, L. (Eds.) Technical Change and Economic Theory. Pinter, London.

Freeman, C., 1995. The national system of innovation in historical perspective. Cambridge Journal of Economics 19, 1, 5-24.

Freeman, C., 2002. Continental, national and sub-national innovation systems complementarity and economic growth. Research Policy 31, 2, 191-211.

Gastrow, M., Lorentzen, J., 2013. Multinational strategies, local human capital and global innovation networks in the automotive industry: the case of Germany and South Africa. Innovation and Development 2, 2, 303-323.

Lall, S., 1992. Technological capabilities and industrialisation. World Development 20, 1, 165-186.

Lall S., 2001. Competitiveness, Technology and Skills. Edward Elgar, Cheltenham.

Lall, S., Kramer-Mbula, E., 2005. Is African industry competing? QEH Working Paper No. 122, University of Oxford.

List, F., 1991 [1841]. The National System of Political Economy. Augustus Kelley, New Jersey.

Lorentzen, J., Muller, L., Manamela, A., and Gastrow, M. 2011. Smart specialisation and global competitiveness: Multinational enterprises and location-specific assets in Cape Town. African Journal of Business Management 5, 12, 4782-4791.

Lundvall, B. (Ed.), 1992. National Systems of Innovation: Towards a Theory of Innovation and Interactive Learning. Pinter, London.

Lundvall, B., 2011. Reflections on an intellectual journey: from a system of innovation pioneer. African Journal of Science, Technology, Innovation and Development 3, 1, 143-148.

Lundvall, B., Johnson, B., Andersen, E., Dalum, B., 2002. National systems of production, innovation and competence building. Research Policy 31, 213-231.

Malerba F., 1999. Sectoral systems of innovation and production. DRUID conference on National Innovation Systems, Industrial Dynamics and Innovation Policy, Rebild, June.

Malerba, F., 2005. Sectoral systems of innovation: a framework for linking innovation to the knowledge base, structure and dynamics of sectors. Economics of Innovation and New Technology 14, 1-2, 63-82.

McCowan, T., Schendel, R., 2015. The impact of higher education on development. In: McGrath, S. and Gu, Q. (Eds.) Routledge Handbook of International Education and Development. Routledge, London.

McGrath, S., Badroodien, A., Kraak, A., Unwin, L. (Eds.), 2004. Shifting Understandings of Skill. HSRC Press, Cape Town. 
McMahon, W., 1999. Education and Development: Measuring the Social Benefits. Oxford University Press, Oxford.

Nelson, R., Winter, S., 1982. An Evolutionary Theory of Economic Change. Harvard University Press, Cambridge, MA.

Nelson, R. (Ed.), 1993. National Innovation Systems: A Comparative Analysis. Oxford University Press, Oxford.

Oketch, M., McCowan, T., Schendel, R., 2014. The Impact of Tertiary Education on Development. Systematic Literature Review for DFID, Institute of Education, London.

Organisation for Economic Cooperation and Development, 2007. OECD Reviews of Innovation Policy: South Africa. Paris: OECD.

Pavlou, P., El Sawy, O., 2011. Understanding the elusive black box of dynamic capabilities. Decision Sciences 42, 1, 239-273.

Pillay, P., 2011. Higher education and economic development: literature review. Cape Town: Centre for Higher Education Transformation.

Salazar-Xirinachs, J., Nübler, I., Kozul-Wright, R., 2014. Industrial policy, productive transformation and jobs: theory, history and practice. In: Salazar-Xirinachs, J., Nübler, I. and Kozul-Wright, R. (Eds.) Transforming Economies. International Labour Organisation, Geneva.

Von Tunzelmann, N., Wang, Q., 2003. An evolutionary view of dynamic capabilities. Economie Appliquée $56,3,33-64$.

Von Tunzelmann, N., Wang, Q., 2007. Capabilities and production theory. Structural Change and Economic Dynamics 18, 2, 192-211.

Von Tunzelmann, N., 2010. Alignment, misalignment and dynamic network-based capabilities. In: Dyker, D. (Ed.) Network Dynamics in Emerging Regions of Europe. Imperial College Press, London.

Walker, M., 2015. Higher education and the public good. In: McGrath, S. and Gu, Q. (Eds.) Routledge Handbook on International Education and Development. Routledge, London.

Winch, C., 1998. Two rival conceptions on vocational education: Adam Smith and Friedrich List. Oxford Review of Education 24, 3, 265-78. 